\title{
Preliminary testing of moisture propagation at timber beam-ends in contact with wet masonry
}

\author{
Lina Nunes ${ }^{\mathrm{a}, \mathrm{b}}$, Maxime Verbist ${ }^{\mathrm{c}}$, Daniel F. Lima ${ }^{\mathrm{c}}$, Jorge M. Branco ${ }^{\mathrm{c} *}$ \\ a LNEC, Structures Department, Lisboa, Portugal \\ $b$ CE3C and University of the Azores, Angra do Heroismo, Portugal \\ c ISISE, Department of Civil Engineering, University of Minho, Guimarães, Portugal
}

\begin{abstract}
The presence in timber structures of signs of biological degradation (fungi and insects) is a frequent problem in old buildings and is strongly correlated with the moisture content of the timber resulting from the exposure to the surrounding environment. Reduction of mechanical performance is a typical result of these events with direct impact in the durability of the structure. The beams present in timber roofs and floors are traditionally supported in direct contact with masonry walls. Considering the conditions that may lead to wood decay, moisture monitoring of timber beam-ends near the contact zone between the elements can give a good estimation of the decay risk. This work presents initial results of the spread of moisture inside experimental Scots pine beams in contact with wet masonry, in order to shed some light on one of the factors of this complex phenomenon.

Peer-review under the responsibility of the organizing committee of the ICMB21.
\end{abstract}

Keywords: timber structures; wet masonry; moisture content; biological degradation.

\section{Introduction and Methods}

The aim of this study is to evaluate and seek to better understand the water absorption and desorption in the direction parallel and perpendicular to the fibers, due to the contact between a timber beam and wet masonry. The variation of the moisture content (MC) can be characterized from four parameters: (i) Equilibrium Moisture Content (EMC), (ii) MC amplitude (A), (iii) MC penetration $\left(\mathrm{l}_{\mathrm{MC}}\right)$ and (iv) $\mathrm{MC}$ gradient $(\mathrm{DMC})$.

The experimental campaign was carried out on three test set ups (Figure 1, samples 1, 4 and 7) that represent the contact between a timber beam and a support masonry with the following elements: (i) Scots pine timber beam-end with 100x160x300 $\mathrm{mm}^{3}$ (three samples); (ii) masonry support for the beam; and, (iii) Six Karsten tubes per test set up applied to the masonry with three particular configurations for simulating the diffusion of water to the wood.

The Configuration I simulates adsorption in both directions (parallel and perpendicular to the fibers) through Karsten tubes positioned on the back and base of the masonry, Configuration II simulates only parallel to the fibers through Karsten tubes positioned only on the back of the masonry, and Configuration III only perpendicular to the fibers through Karsten tubes positioned on the base of the masonry. The Karsten tubes positioned on the back of the masonry aims to simulate the penetration of water from rain associated with wind, in the other hand, the Karsten tubes positioned on the base of the masonry aims to simulate water from wet soil.

To simulate the moistening of the masonry in old buildings (usually consequence of poor maintenance), two cycles composed by a period of moistening and a period of drying were performed. The choice for a drying period aims to simulate periods with low relative humidity, high temperatures, and long periods without rain, common in the Portuguese spring / summer. It was ensured that during the moistening periods the tubes were supplying water to the masonry for at least 6 hours a day. The MC was measured using an electrical resistance moisture meter measuring the timber superficial MC based on a grid spaced by $15 \mathrm{~mm}$. Two reading were made by day. In this way, it is possible to analyze the $2 \mathrm{D}$ distribution of the MC on all faces of the beam. In addition, the timber beam was weighted daily to obtain the amount of total water absorbed or desorbed by the beam during the moistening and drying periods.

\section{Results and discussion}

When water is progressively transferred to the masonry support following the three investigated configurations, the moisture reaches the rear and bottom interfaces between the masonry and the timber sample, leading to moisture propagation on their external surfaces. Figure 1 shows the evolution of the mass of water absorbed in three timber samples (1, 4 and 7$)$ during four testing periods. During the First Moistening Period, the mass of the absorbed water linearly increases with time and can be divided

*351253510200,jbranco@civil.uminho.pt

(C) The Author(s). This is an open access article distributed under the terms of the Creative Commons Attribution License (CC BY) 4.0 https:// creativecommons.org/licenses/by/4.0/, which permits unrestricted use, distribution and reproduction in any medium, provided the original author and source are credited. DOI: 10.14293/ICMB210044 


\section{ICMB21}

into two slopes. The first one is straight and high, implying fast water absorption at the bottom and rear interfaces of the timber. The second slope is fluctuated and lower than the first one, reflecting slow moisture propagation from the bottom and/or rear wet interfaces to the adjoined external surfaces of the timber sample. Unfortunately, the evolution of the mass of absorbed water was not recorded during the First Drying Period, but it is believed that the mass decreased over time since lower values were recorded later during the Second Moistening Period. At the beginning of this period, three samples were not fully dry, and thus reacted differently to the new moisture flow (principle of "Moisture History"). In fact, slower water absorption inside timber samples was observed. During the Second Drying Period, the mass of the absorbed water slightly decreased for the samples 1 and 7, while it remained constant for the sample 4. Only over the last 10 testing days, the mass of absorbed water started to increase for the three timber samples, although the Karsten tubes were kept empty.This was probably due to changes in the relative air humidity of the testing room that was not sealed.

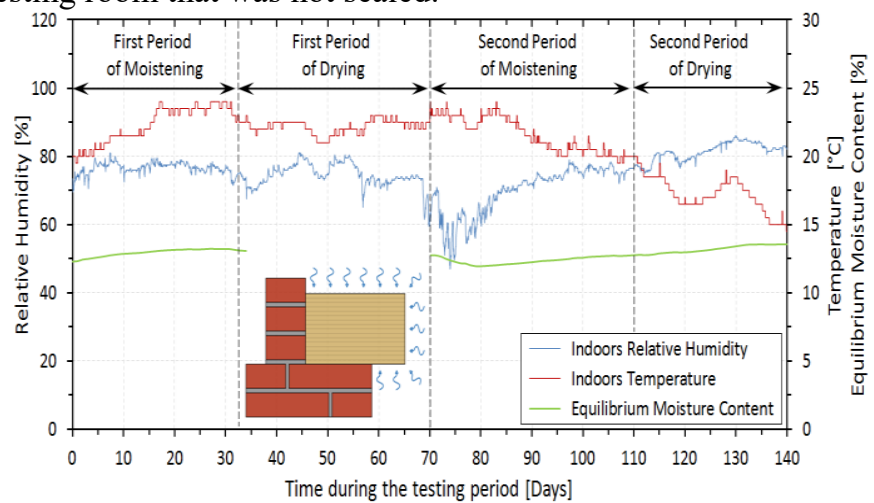

(a)

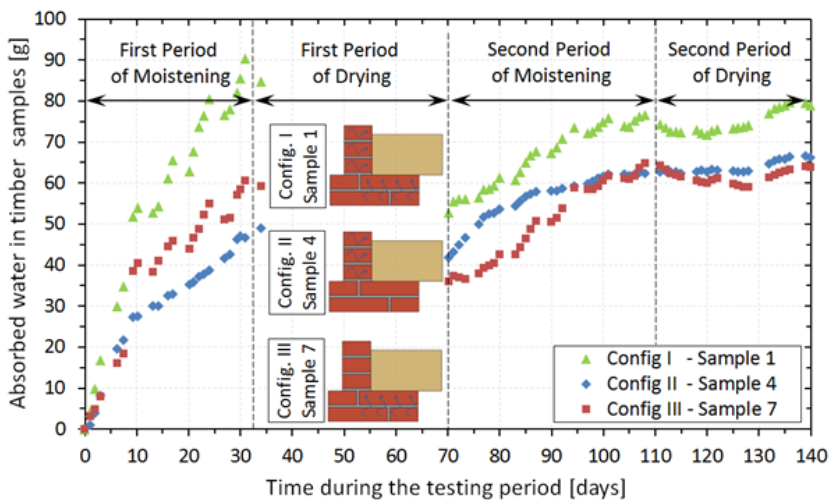

(b)

Figure 1. (a) Evolution of the EMC of timber samples tested, in respect with indoors Relative Humidity and Temperature, during the testing period. Measurements taken from the data logger settled inside the testing room. (b) Evolution of the absorbed water inside timber samples during the testing period.

The samples were not able to dry completely during the two drying periods. The moisture was noticed not only in the water mass measured in the beams, as shown in Figure 1, but also in the superficial MC profiles generated from the measurements made with the electrical resistance moisture meter. It is possible to notice in the three tested samples a high concentration of moisture in the corner where the two faces of the timber are in contact with the wet masonry (faces D and E), as shown in Figure 2.

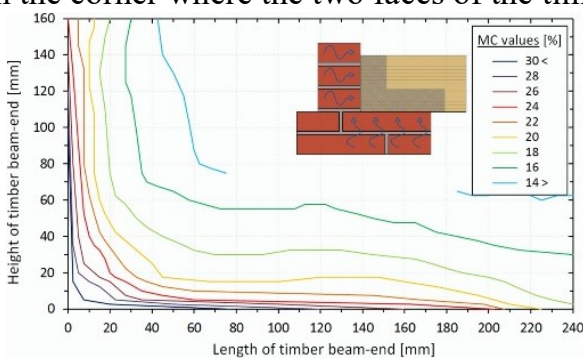

(a)

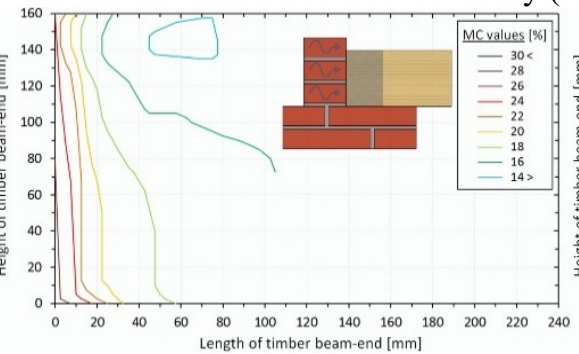

(b)

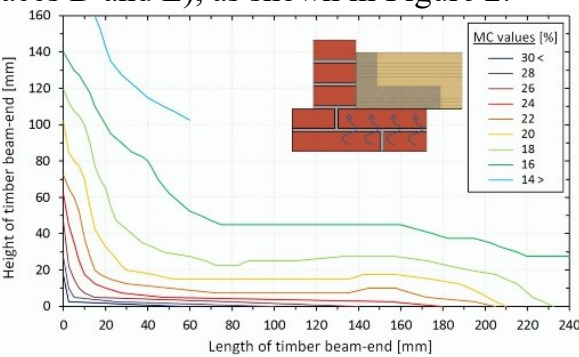

(c)

Figure 2. (a) Maximal curves of wood moisture content (MC) measured on the lateral face (A) of the sample 1 (configuration I, day-139); (b) Maximal curves of wood moisture content (MC) measured on the lateral face (A) of the sample 4 (configuration II, day-139); (c) Maximal curves of wood moisture content (MC) measured on the lateral face (A) of the sample 7 (configuration III, day-139).

\section{Conclusion}

From the preliminary test conducted it was possible to verify that in the first days, the water absorption occurs faster and linearly, and over time, this absorption occurs in a slower and more variable way. Moreover, it was noted that the drying periods were not large enough to allow the timber return to its EMC, in particular, in the corner between the bottom and rear faces and during the second drying period, which may have been influenced by room temperature and relative humidity conditions. Based on the profiles depicted in Figure 2, a point of vulnerability to the attack of biological agents is identified. The $20 \%$ MC, considered in the literature as the value from which the fungal degradation process may start, was identified in an extension of up to $40 \mathrm{~mm}$ in the direction parallel to the fibers and up to $20 \mathrm{~mm}$ in the direction perpendicular to the fibers. In the regions close to the faces, results above $30 \%$ were measured. It is important to note that, even in a short period of time (140 days), it was already possible to observe the appearance of large amounts of mould on the timber beam in contact with the masonry as well as spots of wood discoloration typical of early stages of decay, which highlights the importance of better understanding the phenomenon of moisture transport between these two structural elements. Further testing is currently in progress with the aim to obtain a larger data sample and to improve the test setup. 